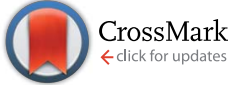

Cite this: J. Mater. Chem. A, 2016, 4, 8875

Received 6th April 2016

Accepted 5th May 2016

DOI: $10.1039 / c 6 t a 02825 j$

www.rsc.org/MaterialsA

\section{Photochemical reduction of carbon dioxide coupled with water oxidation using various soft- oxometalate (SOM) based catalytic systems $\uparrow$}

\author{
Santu Das, Subharanjan Biswas, Tuniki Balaraju, Soumitra Barman, \\ Ramudu Pochamoni and Soumyajit Roy*
}

Simultaneous $\mathrm{CO}_{2}$ reduction and water oxidation as a coupled process is an important challenge in the quest of clean energy production. Herein, we report a metal oxide based heterogeneous catalytic system, which not only couples $\mathrm{CO}_{2}$ reduction with water oxidation, but also provides very high turnover number for $\mathrm{CO}_{2}$ reduction with scalability. Such a catalytic system can simultaneously oxidize water and release the generated electrons for reduction of $\mathrm{CO}_{2}$ with a maximum turnover number and turnover frequency as high as $1.4 \times 10^{6}$ and $610 \mathrm{~s}^{-1}$, respectively, following effective catalyst concentration; whereas, turnover number and turnover frequency is 1366 and $1380 \mathrm{~h}^{-1}$ per mole of catalyst, respectively. The starting materials for this catalytic process are $\mathrm{CO}_{2}$ and water while the end products are oxygen and formic acid and in few cases, formaldehyde. The prospect of using the formic acid generated during our process in fuel cells to generate green energy is also worth mentioning.

\section{Introduction}

Nature performs $\mathrm{CO}_{2}$ reduction and couples it with water oxidation regularly and with very high efficacy in photosynthesis. $\mathrm{CO}_{2}$ emissions are ever increasing. Water and light are amply abundant. Fossil fuel reserves are depleting and upstream $\mathrm{C}_{1}$ feed-stocks demands are steeply increasing. Hence, the immediate question is can $\mathrm{CO}_{2}$ reduction and water oxidation be coupled in a synthetic scalable catalytic system? Herein, we report such a catalytic system based on three different metal oxide based catalysts that can simultaneously oxidize water, and release the generated electrons for the reduction of $\mathrm{CO}_{2}$ with a high TON (turn over number). The starting materials of this catalytic process are $\mathrm{CO}_{2}$ and water while the end products are oxygen and formic acid and in a few cases, formaldehyde. Now we describe briefly the background of our present catalytic process and the development of its design.

Our design of the present catalyst is centred on two phenomena that are coupled together, viz., photo-chemical $\mathrm{CO}_{2}$ reduction $^{1-13}$ and water oxidation. ${ }^{14-22}$ Photochemical $\mathrm{CO}_{2}$ reduction has attracted enormous interest in recent times. During the 1980s Lehn ${ }^{23}$ and Sauvage ${ }^{24}$ pioneered the field of

Eco-Friendly Applied Materials Laboratory (EFAML), Materials Science Centre, Department of Chemical Sciences, Indian Institute of Science Education \& Research, Mohanpur Campus, Kolkata, 741246 West Bengal, India. E-mail: s.roy@iiserkol.ac.in $\dagger$ Electronic supplementary information (ESI) available: Additional characterization and stability of the catalysts during the reactions and product quantification table. CCDC 1057222. For ESI and crystallographic data in CIF or other electronic format see DOI: $10.1039 / \mathrm{c} 6 \mathrm{ta} 02825 \mathrm{j}$ photoelectrochemical $\mathrm{CO}_{2}$ reduction using Re-porphyrins, Co, $\mathrm{Ni}$ cyclams and polyporphyrins, respectively. For $\mathrm{CO}_{2}$ reduction, four prime approaches can be identified as follows. (1) $\mathrm{CO}_{2}$ reduction based on macrocycles such as cyclams with $\mathrm{Ni}^{2+}$ and $\mathrm{Co}^{2+} .{ }^{24,25}$ (2) Polypyrridyl based materials with $\mathrm{Re}^{+}, \mathrm{Ru}^{+}$and $\mathrm{Mn}^{26-29}$ (3) $\mathrm{Pd}^{2+}$ based pincer type complexes reported by Dubois $^{30}$ and the related complexes of Ir pioneered by Peruzzini. ${ }^{31}$ (4) Cantat and co-workers have pioneered metal free $\mathrm{CO}_{2}$ reduction using nitrogen containing bases such as amidines and guanidines with hydrosilanes as the reducing agents. ${ }^{32}$ Molybdenum alone has been shown to be capable of $\mathrm{CO}_{2}$ reduction. ${ }^{33}$ Likewise, water oxidation by metal complexes has also attracted enormous attention since the seminal concept of artificial photosynthesis proposed by Nocera. ${ }^{2}$ The use of optical semi-conductors coupled with a metal complex for $\mathrm{CO}_{2}$ reduction has been very recently proposed..$^{33}$ The possibility of achieving scalable coupled $\mathrm{CO}_{2}$ reduction with water oxidation has also been proposed. ${ }^{2,4}$ However, to date and to the best of our knowledge, no scalable approach for the realization of this effort has been reported. Some related noteworthy efforts warrant mention. For instance, Carpenter and co-workers have explored the possibility of $\mathrm{CO}_{2}$ reduction without the presence of any external reducing agent. ${ }^{9}$ With a prototype example of an amine, they have shown this reduction in an indirect fashion. ${ }^{12}$ More recently, Yang et $a .^{34}$ have shown the possibility of coupling of $\mathrm{CO}_{2}$ reduction and water oxidation with nanocomposites of tantalum-based pyrochlore nanoparticles and indium hydroxide where pyrochlore nanoparticles catalyze the $\mathrm{CO}_{2}$ reduction reaction or water reduction reaction and indium hydroxide catalyzes water oxidation. Though a very elegant 
effort, this method also suffers from a negligible turnover number. In another effort, Kudo et $a l^{35}$ reported a method coupling Ag co-catalyst loaded perovskites with the formula of $\mathrm{ALa}_{4} \mathrm{TiO}_{4} \mathrm{O}_{15}(\mathrm{~A}=\mathrm{Ca}, \mathrm{Sr}$ and $\mathrm{Ba})$. The catalyst, although couples $\mathrm{CO}_{2}$ reduction with water oxidation with simultaneous formation of $\mathrm{HCOOH}$ and $\mathrm{CO}$, provides only a negligible yield (maximum $\mathrm{CO}$ yield is 22 micromoles per hour with $0.3 \mathrm{~g}$ catalyst loading). The single catalysis electrocatalytic $\mathrm{CO}_{2}$ reduction coupled with water oxidation reported by Meyer group $^{36,37}$ also deserves a mention. They have shown that a $\mathrm{Ru}$ (II) polypyridyl carbene complex can catalyze the electrochemical reduction of $\mathrm{CO}_{2}$ in water with added bicarbonate to give synthesis gas $\left(\mathrm{H}_{2}\right.$ and $\left.\mathrm{CO}\right)$ mixtures at the cathode and water oxidation to $\mathrm{O}_{2}$ at the anode. However, the problems of low turnover numbers and scalability also occur. The issue of scalability has been addressed in the recent work of the Yaghi and Chang group. ${ }^{1}$ They have shown that cobalt-porphyrin based covalent organic frameworks can be optimized to synthesize the catalytic material, which shows very high efficiency towards the reduction of $\mathrm{CO}_{2}$ to $\mathrm{CO}$. The faradaic efficiency of this reaction was $90 \%$ with turnover numbers up to 290000 , with an initial turnover frequency of $9400 \mathrm{~h}^{-1}$.

Here we take the next step. To perform photochemical $\mathrm{CO}_{2}$ reduction coupled with the water oxidation reaction, we chose a set of various metal oxide clusters. It is already known from earlier studies that metal oxide clusters can act as active and efficient photocatalysts $^{37,38}$ as well electrocatalysts ${ }^{39,40}$ in water oxidation and water reduction ${ }^{\mathbf{4 1 , 4 2}}$ reactions. These metal oxide clusters are also cheap and green. To enhance the effective surface area of the catalysts, instead of using the metal oxides in the solid phase, we have prepared self-assembled vesicles with the metal oxides. Such vesicle-like super-structure formation of the metal oxide clusters is well known and studied by our group and we have proposed them to be called soft-oxometalates (SOMs). ${ }^{43-50}$ Very recently we have exploited various properties of SOMs and thereby, their usability in a large range of applications have been explored. SOMs can undergo topological transformation, ${ }^{51}$ can be used in patterning ${ }^{52,53}$ and as active particles. ${ }^{46}$ The catalytic activity of SOMs has also been explored in various types of reactions viz., in photo-polymerization ${ }^{54-56}$ and photochemical water oxidation. ${ }^{57}$ In this article we have shown that SOM type materials based on oxo-molybdate and oxo-tungstate clusters can efficiently catalyse the reduction of $\mathrm{CO}_{2}$ to $\mathrm{HCOOH} / \mathrm{HCHO}$ by transferring the electrons and protons generated from oxidation of water. The catalysts reported here present a new opportunity as they provide a method that is scalable and fast with a very high turnover number.

\section{Results and discussion}

\section{About the catalysts}

We applied the design principles in heterogeneous catalysis mode to render the process scalable and rapid. Following the above design principle three catalysts were synthesized (Fig. 1):

$$
\left\{\mathrm{Mo}_{154}\right\}_{x} \text {, where } x=1165
$$

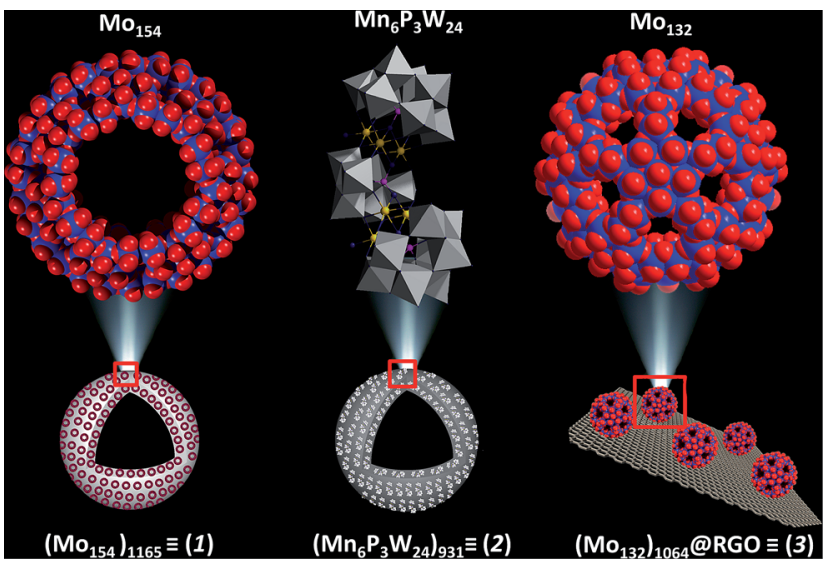

Fig. 1 The structures of the three catalysts, $\left\{\mathrm{Mn}_{6} \mathrm{P}_{3} \mathrm{~W}_{24}\right\}$ is shown in polyhedral representation while $\left\{\mathrm{MO}_{154}\right\}$ and $\left\{\mathrm{MO}_{132}\right\}$ are shown as a space-filling model. Color code: Mo, red; O, blue; Mn, yellow; W, grey; P, pink.

$$
\begin{gathered}
\left\{\mathrm{Mn}_{6} \mathrm{P}_{3} \mathrm{~W}_{24}\right\}_{y}, \text { where } y=931 \\
\left\{\mathrm{Mo}_{132}\right\}_{n} @ \mathrm{RGO}, \text { where } n=1064
\end{gathered}
$$

where RGO stands for reduced graphene oxide.

Before preparing the effective catalysts we first briefly introduce the metal oxide based molecular precursors of the catalysts. We chose three metal oxide based clusters viz. $\left\{\mathrm{Mo}_{154}\right\}$, $\left\{\mathrm{Mn}_{6} \mathrm{P}_{3} \mathrm{~W}_{24}\right\}$ and $\left\{\mathrm{Mo}_{132}\right\}$.

\section{Molecular structure of $\mathbf{M o}_{154}$}

$\left\{\mathrm{Mo}_{154}\right\}$ is a giant wheel-shaped mixed-valence polyoxomolybdate cluster with the formula $\left\{\mathrm{Mo}_{154} \mathrm{O}_{462} \mathrm{H}_{14}\left(\mathrm{H}_{2}\right.\right.$ O) $\left.)_{70}\right\}^{14-}$ comprising $140\left\{\mathrm{MoO}_{6}\right\}$ octahedra and 14 pentagonal bipyramids of the type $\left\{\mathrm{MoO}_{7}\right\} .{ }^{58}$ It can be described as a tetradecamer comprising $14\left\{\mathrm{Mo}_{8}\right\}$ units with a central $\left\{\mathrm{MoO}_{7}\right\}$ group. This $\left\{\mathrm{MoO}_{7}\right\}$ is symmetrically connected to five $\left\{\mathrm{MoO}_{6}\right\}$ octahedra by edge sharing. This builds a $\left\{(\mathrm{Mo}) \mathrm{Mo}_{5}\right\}$ pentagon. Four of the $\left\{\mathrm{MoO}_{6}\right\}$ octahedra are linked to further $\left\{\mathrm{MoO}_{6}\right\}$ octahedra via corner sharing to form the $\left\{\mathrm{Mo}_{8}\right\}$ unit. The two $\mathrm{MoO}_{6}$ octahedra, which are not directly connected to the central $\mathrm{MoO}_{7}$ bipyramid are fused to neighbouring $\left\{\mathrm{Mo}_{8}\right\}$ units through corners. Neighbouring $\left\{\mathrm{Mo}_{8}\right\}$ groups are additionally fused together by the $\left\{\mathrm{Mo}_{2}\right\}$ units, thereby completing the inner-ring parts of the upper and lower half of the ring structure. The complete construction of the ring is achieved by fusing the second half through the $14\left\{\mathrm{Mo}_{1}\right\}$ groups at the equator after rotating around $360 / 14^{\circ}$ relative to the first. Thus, the 'giantwheel' can be formed in terms of the three different building blocks as $\left[\left\{\mathrm{Mo}_{2}\right\}_{14}\left\{\mathrm{Mo}_{8}\right\}_{14}\left\{\mathrm{Mo}_{1}\right\}_{14}\right]^{14-}$.

We have synthesized crystals of these giant-wheel like molybdenum blue compound, $\left\{\mathrm{Na}_{15}\left[\left\{\mathrm{Mo}_{126}\right\}^{\mathrm{VI}}\left\{\mathrm{Mo}_{28}\right\}^{\mathrm{V}} \mathrm{O}_{462} \mathrm{H}_{14}\right.\right.$ $\left.\left.\left(\mathrm{H}_{2} \mathrm{O}\right)_{70}\right]_{0.5}\left[\left\{\mathrm{Mo}_{124}\right\}^{\mathrm{VI}}\left\{\mathrm{Mo}_{28}\right\}^{\mathrm{V}} \mathrm{O}_{457} \mathrm{H}_{14}\left(\mathrm{H}_{2} \mathrm{O}\right)_{68}\right]_{0.5} \cdot c a . \quad 400 \mathrm{H}_{2} \mathrm{O}\right\}$ following a literature procedure. ${ }^{59}\left\{\mathrm{Mo}_{154}\right\}$ has a space group $P \overline{1}$. It is characterized by FT-IR (Fig. 2a), resonance Raman spectroscopy (Fig. 2b) and SEM (Fig. 3a). The IR spectrum shows characteristic peaks at $1629\left(\delta_{\mathrm{H}_{2} \mathrm{O}}\right), 1409,1308,1015,955$ 
a)
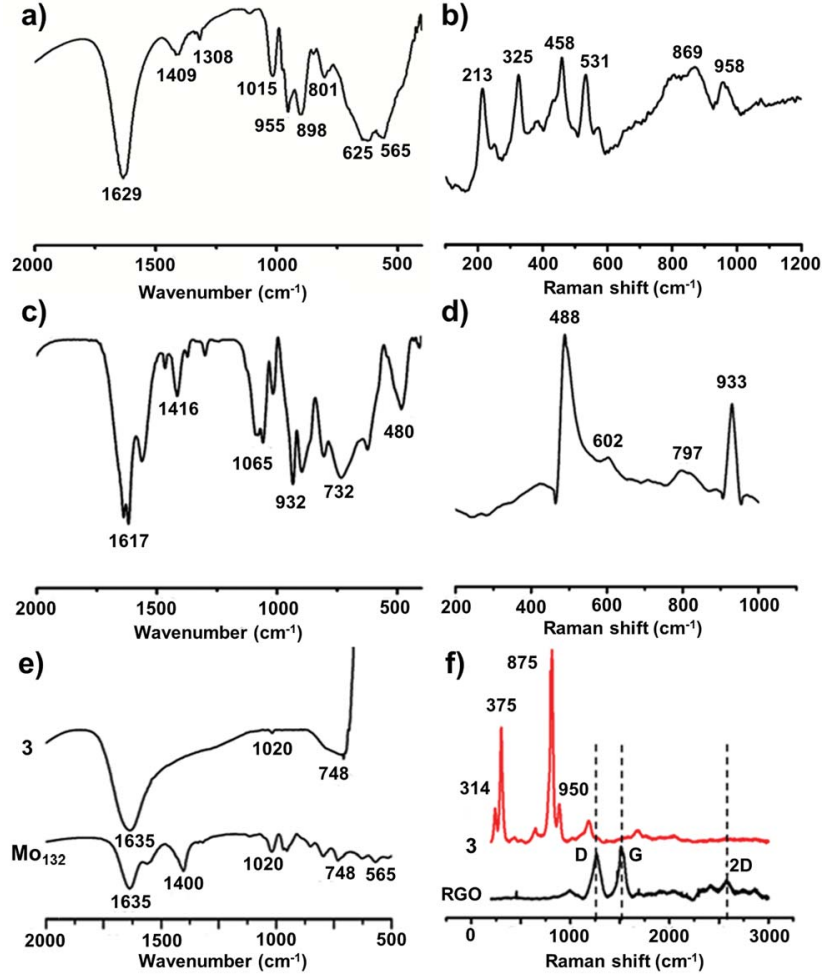

d)
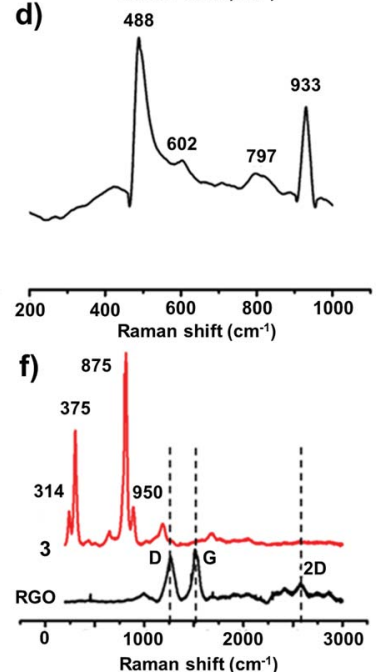

Fig. 2 Characterization of all the catalysts by FT-IR and Raman spectroscopy, from the top to bottom row: catalyst 1,2 and 3 . The presence of characteristics bands in the FT-IR $(a, c, e)$ and Raman (b, d, f) spectra are observed for all the catalysts. In the Raman spectrum of catalyst $3\left(\mathrm{Mo}_{132}(\mathrm{RGO})\right.$, characteristic $\mathrm{D}$ and $\mathrm{G}$ bands are shifted somewhat, which might be due to the interaction of $\mathrm{MO}_{132}$ with the RGO surface.

$\left(\nu_{\mathrm{Mo}=\mathrm{O}}\right), 898,801,625$ and $565 \mathrm{~cm}^{-1} \cdot{ }^{59}$ Using an excitation of the $1064 \mathrm{~nm}$ band, a resonance-Raman spectrum is obtained with five bands characteristic for the molybdenum blue species at 802 ( $\left.\nu_{\text {asMo-O }}\right), 531,458,325\left(\delta_{\text {O-Mo-O }}\right)$ and $215\left(\nu_{\text {asMo-O }}\right) \mathrm{cm}^{-1}{ }^{60}$ The electronic absorption spectrum is dominated by two bands characteristic for molybdenum blue species at 745 and $1076 \mathrm{~nm}$ (Fig. 4a). The first maxima is assigned to intervalence $\left(\mathrm{Mo}^{\mathrm{V}} / \mathrm{Mo}^{\mathrm{VI}}\right)$ charge transfer transitions (IVCT) and the second maxima corresponds to the abundance of $28 \mathrm{Mo}^{\mathrm{V}}$ centers. ${ }^{61}$

\section{On active catalyst (1)}

Synthesis and characterization of $\left\{\mathbf{M o}_{154}\right\}_{1165}$ superstructures. The active catalyst is a SOM i.e., dispersion of $\left\{\mathrm{Mo}_{154}\right\}$ in water. $\left\{\mathrm{Mo}_{154}\right\}$ undergoes self-assembly in a dispersion to form a vesicle-like SOM superstructure (1). Each vesicle-like SOM contains $1165\left\{\mathrm{Mo}_{154}\right\} .^{.2}$ The structure is designated to have the following formula: $\left\{\mathrm{Mo}_{154}\right\}_{1165}$. Here 1165 rings are icosahedrally placed around 12 vertices of the quasi-icosahedron. The structure is a hollow shell of $\left\{\mathrm{Mo}_{154}\right\}$ rings, whose cavity and exterior are filled with water molecules. The SEM image indicates the spherical nature of the vesicles with dimension near about $50 \mathrm{~nm}$. The dynamic light scattering study of 1 determines the hydrodynamic radius of the SOM 1 as $51 \mathrm{~nm}$ (Fig. 4d).
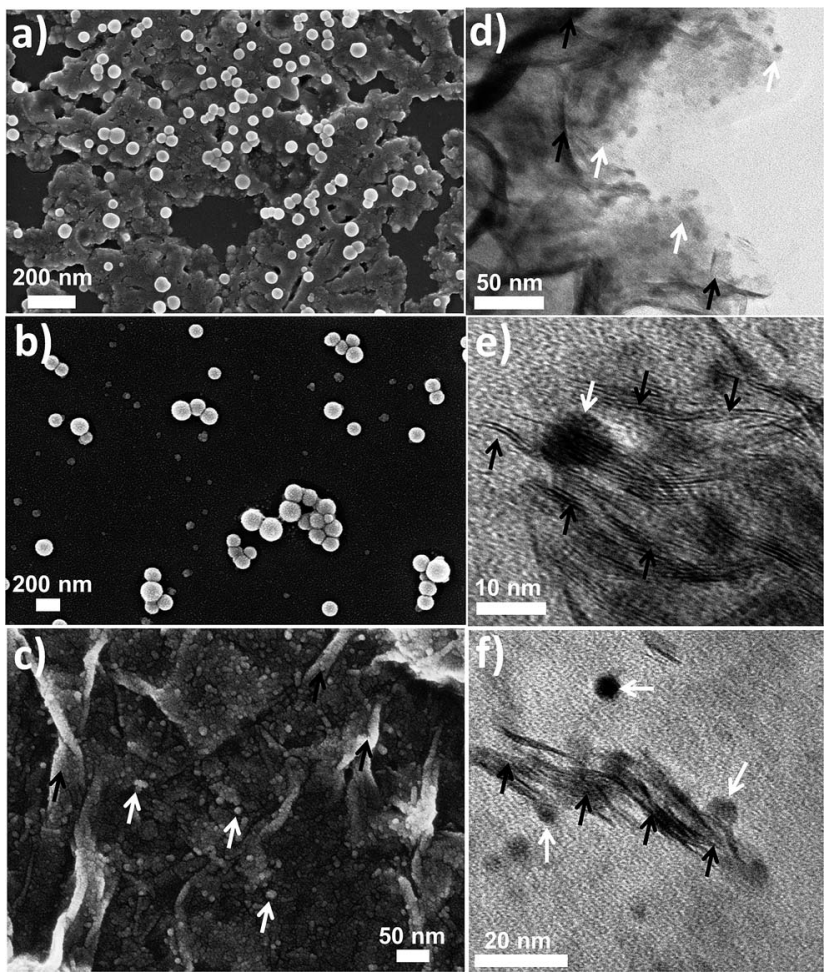

Fig. 3 (Left column) SEM images of 1, 2 and 3 (a, b \& c, respectively). Vesicle like morphology is seen in the case of 1 and 2. (Right column) TEM image of 3 is shown in $d-f$. Both SEM $\&$ TEM images of 3 show embedded $\mathrm{MO}_{132}$ spheres on the surface of RGO sheet. Curves of RGO sheets are shown by black arrows while white arrows indicate $\mathrm{Mo}_{132}$ spheres.

\section{Molecular structure of $\left\{\mathbf{M n}_{6} \mathbf{P}_{3} \mathbf{W}_{24}\right\}$}

This polyoxometalate has the formula, $\left\{\mathrm{Mn}_{6} \mathrm{P}_{3} \mathrm{~W}_{24} \mathrm{O}_{94}\left(\mathrm{H}_{2^{-}}\right.\right.$ $\left.\mathrm{O}_{2}\right\}^{17-}$ (Fig. 1). It crystalizes in a monoclinic unit cell, which consists of two Keggin type $\left\{\mathrm{Mn}_{3} \mathrm{PW}_{9} \mathrm{O}_{34}\right\}$ units linked by one $\left\{\mathrm{PW}_{6} \mathrm{O}_{24}\right\}$ unit. The synthesized POM has $C_{2 v}$ symmetry with a banana shape. The molecular structure may also be called a double sandwiched structure that implies the presence of two distinct $\left\{\mathrm{Mn}_{3} \mathrm{O}_{13}\right\}$ triads formed by octahedral units of $\left\{\mathrm{MnO}_{6}\right\}$. In this structure, all six of the Mn centers are not in similar environment as one of the terminal Mn atoms from each Keggin type cage are coordinated with a water molecule. The Mn-Mn distance in the crystals are not all identical with a minimum distance of $3.30 \AA ̊$ and maximum distance of $3.35 \AA$ A. From these $\mathrm{Mn}-\mathrm{Mn}$ distances we can conclude that there is no $\mathrm{Mn}-\mathrm{Mn}$ magnetic coupling possible in the molecule. The oxidation state of manganese is +II, which is confirmed from bond valance sum method. ${ }^{63}$ The characteristic FT-IR peaks $\left(\mathrm{cm}^{-1}\right)$ are: 1617 $\left(\delta_{\mathrm{H}_{2} \mathrm{O}}\right), 1065\left(\nu_{\mathrm{P}-\mathrm{O}}\right), 932\left(\nu_{\mathrm{W}=\mathrm{O}}\right), 730\left(\nu_{\mathrm{W}-\mathrm{O}-\mathrm{W}}\right)$ and $480\left(\nu_{\mathrm{Mn}-\mathrm{O}}\right)$ $\mathrm{cm}^{-1}$ (Fig. 2c). The Raman peaks $\left(\mathrm{cm}^{-1}\right)$ at: 488, 602, 797 and 933 are attributed to $\left(\nu_{\mathrm{as}, \mathrm{Mn}-\mathrm{O}}\right),\left(\nu_{\mathrm{W}=\mathrm{O}}\right)$ and $\left(\nu_{\mathrm{P}-\mathrm{O}}\right)$, respectively (Fig. 2d). From EAS spectroscopy, the absorption maximum is found to be at $250 \mathrm{~nm}$ (Fig. 4b). The structure can be obtained in the CCDC database by quoting the CCDC no. 1057222.

A detailed account of the synthesis of $\left\{\mathrm{Mn}_{6} \mathrm{P}_{3} \mathrm{~W}_{24}\right\}$ is given in the experimental section. 

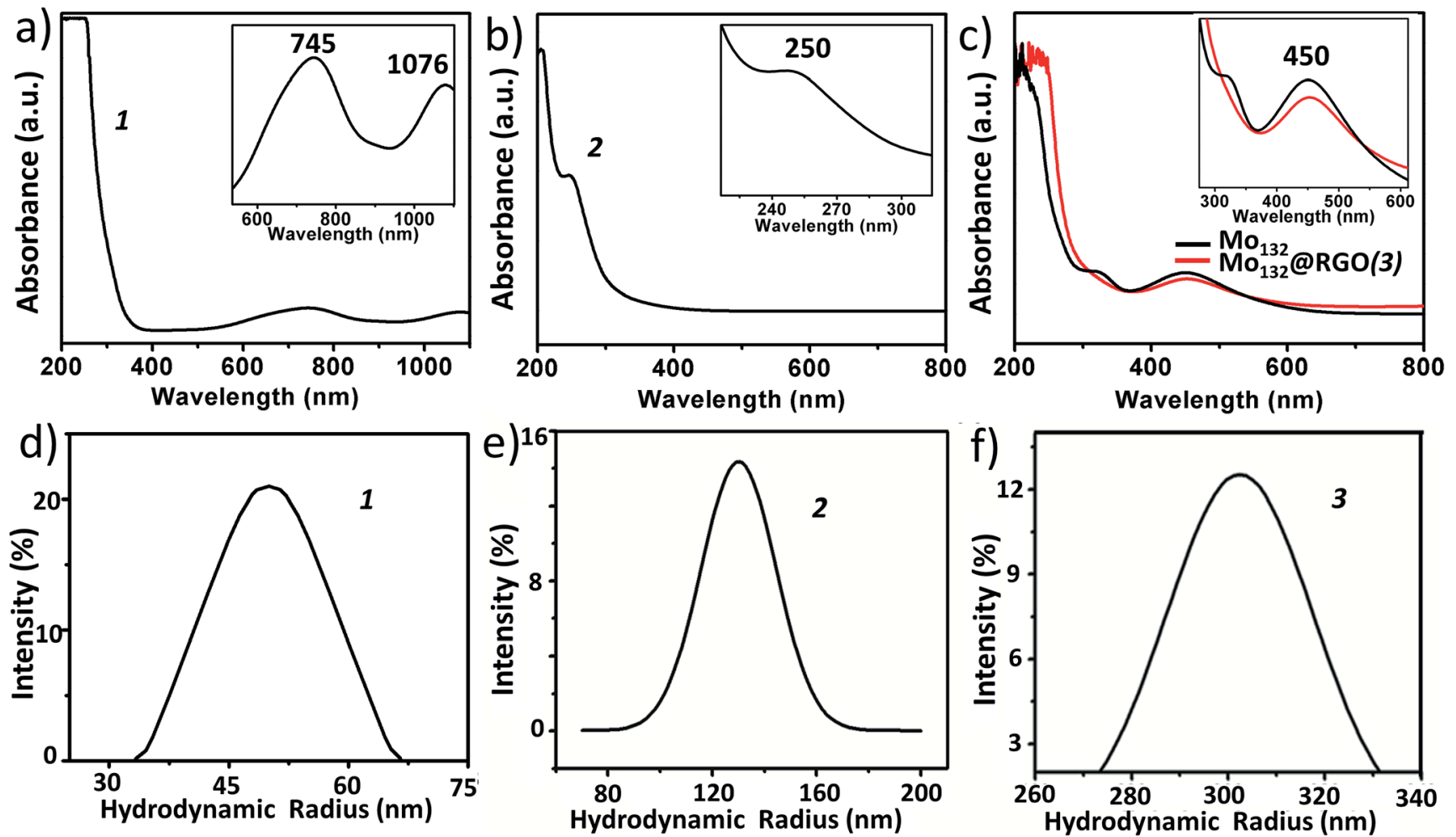

Fig. 4 UV-Vis spectroscopy of 1, 2 and 3 (upper panel) shows characteristic bands for $\left\{\mathrm{Mo}_{154}\right\}(745$ and $1076 \mathrm{~nm}),\left\{\mathrm{Mn}_{6} \mathrm{P}_{3} \mathrm{~W}_{24}\right\}(250 \mathrm{~nm})$ and $\left\{\mathrm{MO}_{132}\right\}(450 \mathrm{~nm})$. The magnified characteristics bands are shown in the insets. The lower panel represents the hydrodynamic radius obtained from DLS spectroscopy of 1, 2 and 3 with an average of 51, 130 and $300 \mathrm{~nm}$, respectively.

On active catalyst (2)

Synthesis and characterization of $\left\{\mathbf{M n}_{6} \mathbf{P}_{3} \mathbf{W}_{24}\right\}_{931}$ based SOMs. Taking the solid crystals, we prepared the SOMs of $\left\{\mathrm{Mn}_{6} \mathrm{P}_{3} \mathrm{~W}_{24}\right\}$ in water. A dispersion of SOMs is prepared by just shaking crystals of $\left\{\mathrm{Mn}_{6} \mathrm{P}_{3} \mathrm{~W}_{24}\right\}$ in water. We obtain a dispersion full of blackberry type self-assembled $\mathrm{SOMs}^{43,44}$ as observed from the SEM images (Fig. 3b). Each vesicle contains 931 $\left\{\mathrm{Mn}_{6} \mathrm{P}_{3} \mathrm{~W}_{24}\right\}$ units. From the EDS experiment we have shown the ratio of $\mathrm{P}: \mathrm{Mn}: \mathrm{W}$ in crystal is $1: 2.22: 8.3$, which is very close to the ratio found in the crystal structure of compound $\left\{\mathrm{Mn}_{6} \mathrm{P}_{3} \mathrm{~W}_{24}\right\}$. The hydrodynamic radius of 2 is measured from the DLS experiment, which shows an average hydrodynamic radius of $130 \mathrm{~nm}$ (Fig. 4e). The SEM image also indicates the radius of the vesicles is around $150 \mathrm{~nm}$ (Fig. 3b). We used this SOM dispersion of 2 as an active catalyst in our experiments.

\section{Molecular structure of $\mathbf{M o}_{132}$}

$\left\{\mathrm{Mo}_{132}\right\}$ of the formula $\left\{\mathrm{Mo}_{132} \mathrm{O}_{372}\left(\mathrm{CH}_{3} \mathrm{COO}\right)_{30}\left(\mathrm{H}_{2} \mathrm{O}\right)_{72}\right\}^{42-}$ is a type of molybdenum brown "Keplerate" anion with a diameter of $2.9 \mathrm{~nm}$. This spherical cluster contains 132 molybdenum centers of which 72 molybdenum centers are in the +VI oxidation state and the remaining 60 molybdenum centers are in the $+\mathrm{V}$ oxidation state. The dark brown color of $\mathrm{Mo}_{132}$ arises due to intervalence charge transfer between the $\mathrm{Mo}^{\mathrm{V}}$ and $\mathrm{Mo}^{\mathrm{VI}}$ centers. Such a Keplerate cluster assembled with acetate as the ligand has an icosahedral point group symmetry. 12 pentagonal $\{(\mathrm{Mo})$
$\left.\mathrm{Mo}_{5}\right\}$ building blocks are disposed at twelve vertices of an icosahedron. Such disposition creates space for 30 linkers on the icosahedron's surface, which simultaneously link to the prevalent pentagonal building blocks. Omitting the oxygen atoms for the sake of simplicity, the linkers are $\left\{\mathrm{Mo}_{2}\left(\mathrm{CH}_{3} \mathrm{COO}\right)\right\}$ in the case of $\left\{\mathrm{Mo}_{132}\right\}$. Hence, the overall cluster formulation can de described as [pentagon $]_{12}[\text { linker }]_{30}$ or $\left\{(\mathrm{Mo}) \mathrm{Mo}_{5}\right\}_{12^{-}}$ $\left\{\mathrm{Mo}_{2} \text { (acetate) }\right\}_{30}$ or $\left.\left\{\mathrm{Mo}_{132} \text { (acetate }\right)_{30}\right\}$ or $\left\{\mathrm{Mo}_{132}\right\}$ or $\left\{\mathrm{Mo}_{132} \mathrm{O}_{372^{-}}\right.$ $\left.\left(\mathrm{CH}_{3} \mathrm{COO}\right)_{30}\left(\mathrm{H}_{2} \mathrm{O}\right)_{72}\right\}^{42-}$.

The IR spectrum (Fig. 2e) shows main peaks at $1635\left(\delta_{\mathrm{H}_{2} \mathrm{O}}\right)$, $1400\left(\delta_{\mathrm{CH}_{3}}, \nu_{\mathrm{SCOO}}, \delta_{\mathrm{asNH}_{4}}{ }^{+}\right), 1020,748$ and $565 \mathrm{~cm}^{-1} \cdot{ }^{59}$ Raman bands (Fig. 2f) are observed at $950\left(\nu_{\mathrm{Mo}=\mathrm{O}}\right), 875,375$ and 314 $\mathrm{cm}^{-1}$ and correspond to the irreducible representations, $\mathrm{H}_{\mathrm{g}}$ and $\mathrm{A}_{1 \mathrm{~g}}$ (bands with the highest intensity). The electronic absorption spectrum shows an intense band at $450 \mathrm{~nm}$ owing to Mo $\leftarrow \mathrm{O}$ charge transfer (Fig. 4c).

$\mathrm{Mo}_{132}$ was synthesized following a literature procedure. ${ }^{59}$

\section{On active catalyst (3)}

Synthesis and characterization of $\left\{\mathbf{M o}_{132}\right\}_{1064} @ R G O$. Since it is known that $\mathrm{Mo}_{132}$ self-assembles in an aqueous solution to form a SOM superstructure in dispersion. ${ }^{64}$ We then made a new composite material of $\mathrm{Mo}_{132}$ with reduced graphene oxide (RGO). We synthesized RGO following a literature procedure. ${ }^{65}$ The $\mathrm{Mo}_{132} @$ @GO composite SOM (3) was prepared by sonication of a solution of $\mathrm{Mo}_{132}$ with RGO and is characterized by HATR-IR (Fig. 2e), Raman (Fig. 2f) and UV-Vis spectroscopy 


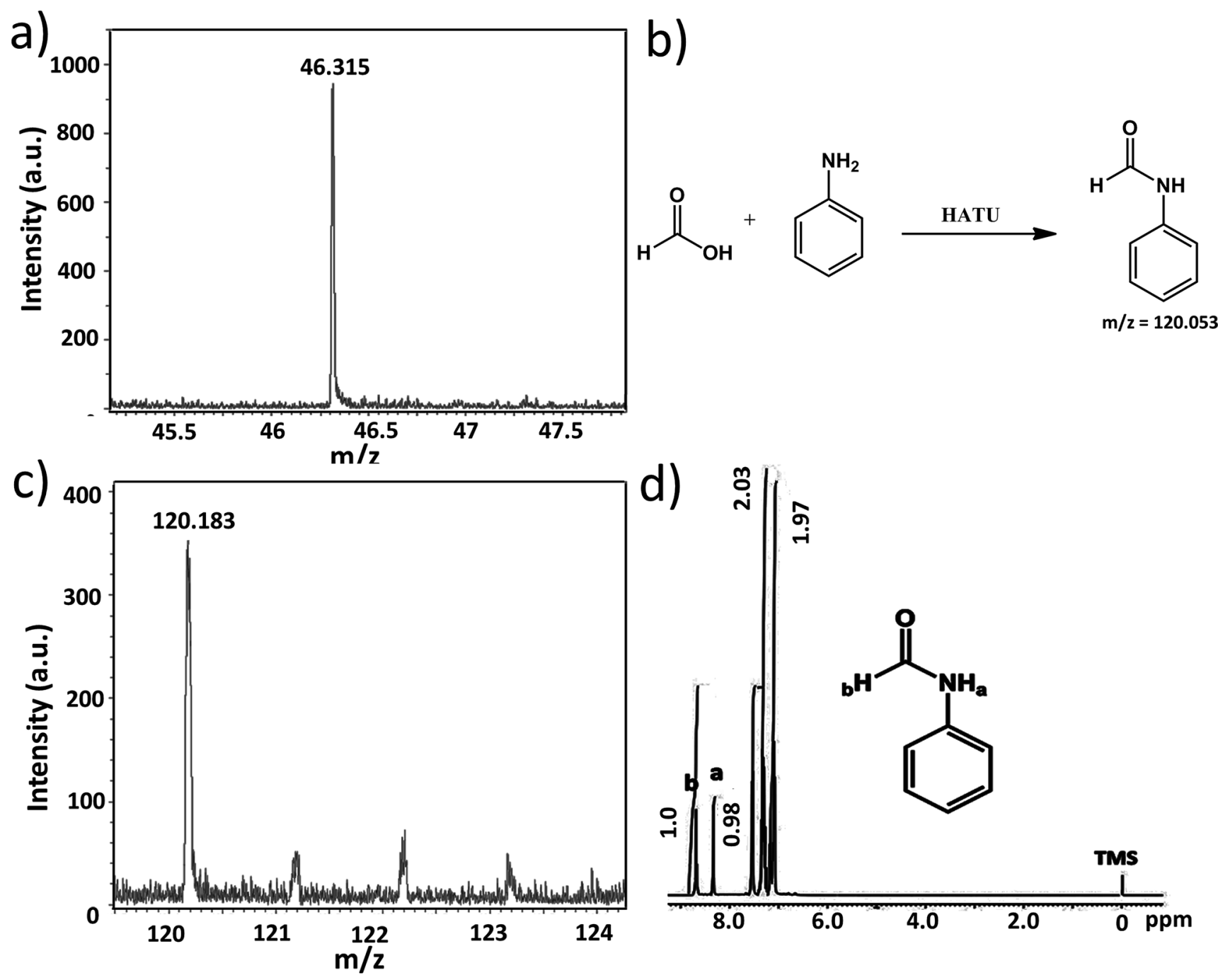

Fig. 5 (a) MALDI-MS of the product after $\mathrm{CO}_{2}$ reduction. The formation of formic acid is observed as a peak is seen at 46.31 . (b) The reaction of aniline coupling to form amide. (c) MALDI-MS of amide. (d) NMR of amide formed.

(Fig. 4c). The morphology of the composites in the corresponding dispersion was obtained from SEM and TEM (Fig. 3c and $\mathrm{d}-\mathrm{f}$, respectively). From the microscopy images it is observed that $\mathrm{Mo}_{132}$ single clusters are embedded on the surface of RGO. This depicts the nature of 3. In the Raman spectrum we find the characteristics peaks of RGO are slightly shifted in the composite material, which may be due to the interaction of the attached $\mathrm{Mo}_{132}$ with the RGO surface. All the characteristic peaks of $\mathrm{Mo}_{132}$ are retained in the Raman spectrum, which indicates the integrity of $\mathrm{Mo}_{132}$ is retained in the composite. The DLS experiment further reveals that the average hydrodynamic radius of the composite material is $300 \mathrm{~nm}$ (Fig. 4f). The zeta potential of the composite material is $-40 \mathrm{mV}$, which indicates that the dispersion is negatively charged stabilized due to anionic $\left\{\mathrm{Mo}_{132}\right\}$ in the reaction mixture (Fig. S10†). $1064 \mathrm{Mo}_{132}$ cluster molecules are said to be involved to form a single SOM super-structure in the $\mathrm{Mo}_{132} @$ RGO composite, which is the active catalyst. It is to be noted that the photochemical reduction of $\mathrm{CO}_{2}$ coupled with water oxidation is achieved by incorporation of three modular functions via these metal-oxide based frameworks. (1) Simultaneous photo-activation of thousands of metal centres (electron and hole generation) to oxidize water, (2) water oxidation $\left(\mathrm{O}_{2}\right.$, proton and electron generation) and (3) concomitant transfer of the generated protons and electrons to reduce $\mathrm{CO}_{2}$ to $\mathrm{HCOOH} / \mathrm{HCHO}$ by the catalyst framework.

Now we describe the catalytic activity of $\mathbf{1}, \mathbf{2}$, and 3 in the matter of the photochemical $\mathrm{CO}_{2}$ reduction reaction.

\section{Photocatalytic reduction of $\mathrm{CO}_{2}$}

In our present case we used $\mathbf{1}, 2$ and 3 as photocatalysts for photochemical $\mathrm{CO}_{2}$ reduction. Among the three catalysts, $\mathbf{1}$ and 2 are one component catalysts while 3 is a two component catalyst. RGO is used for the facile transport of electrons. The principle product of $\mathrm{CO}_{2}$ reduction is formic acid; however, we have also obtained formaldehyde in significant amounts with catalysts 1 and 3. In terms of formic acid production, with respect to every unit of super-structure, 3 gives a maximum yield 
of formic acid of $205 \mu \mathrm{mol}$ with a turnover number of $\mathrm{ca}$. $1.4 \times$ $10^{6}$ in water (while per mole turnover number is 1366). On the other hand, 1 and 2 gives a TON of $0.9 \times 10^{6}$ and $0.25 \times 10^{6}$ (whereas, per mole values are $778 \& 270$ ), respectively, at 0.15 $\mu \mathrm{mol}$ loading (for details on the turnover number calculation see later). Here water gets oxidized to produce oxygen, protons and electrons; these protons and electrons are responsible for the reduction of $\mathrm{CO}_{2}$.

The formation of formic acid was first characterized by matrix-assisted laser desorption ionization-mass spectroscopy (MALDI-MS) using a $\alpha$-cyano-4-hydroxycinnamic acid matrix (Fig. 5a) and quantified by high performance liquid chromatography (HPLC) (against an external standard $0.1 \mathrm{M}$ formic acid). Furthermore, the produced formic acid was characterized by coupling it with aniline in the presence of HATU (1-[bis(dimethylamino)methylene]-1 $H$-1,2,3-triazolo[4,5- $b]$ pyridinium 3-oxid hexafluorophosphate) as a coupling agent to form the amide (Fig. 5b), which was detected by MALDI-MS using an HCCA matrix (Fig. 5c) and ${ }^{1} \mathrm{H}$ NMR spectroscopy (Fig. 5d). The generation of formaldehyde in the reaction mixture was quantified using HPLC (against an external standard of $0.1 \mathrm{M}$ formaldehyde). Formaldehyde was obtained only in the case of
1 and $3 ; 2$ selectively reduced $\mathrm{CO}_{2}$ to formic acid. No other gaseous reduced product was formed during the course of $\mathrm{CO}_{2}$ reduction as confirmed by gas chromatography-mass spectroscopy (GC-MS). Formation of formic acid was further confirmed from the cyclic voltammogram (CV) where we observed a peak around $-0.60 \mathrm{~V} v s$. $\mathrm{Ag} / \mathrm{AgCl}$ electrode, which corresponds to the reduction potential of $\mathrm{CO}_{2} / \mathrm{HCOOH}$ (Fig. 6a). Simultaneously water oxidation during the course of $\mathrm{CO}_{2}$ reduction was characterized using an YSI Clark type electrode. Further confirmation of water oxidation was obtained from the CV where we observed a sharp increase in current at $1.2 \mathrm{~V} v$ s. $\mathrm{Ag} / \mathrm{AgCl}$ electrode (Fig. 6a), typical of water oxidation. All the reactions were carried out at least five times \& the average data for the five sets were taken and analysed accordingly.

Next we performed time-dependent experiments to investigate the kinetics of the reaction. It was observed that for $\mathbf{1}$ and $\mathbf{3}$ the reaction is almost completed within 40 minutes (Fig. $6 \mathrm{~b}$ and i), while 2 takes 75 minutes to complete the reaction (Fig. 6b). These reactions are relatively rapid. This is probably due to the presence of a large number of active catalytic centers in our catalysts.
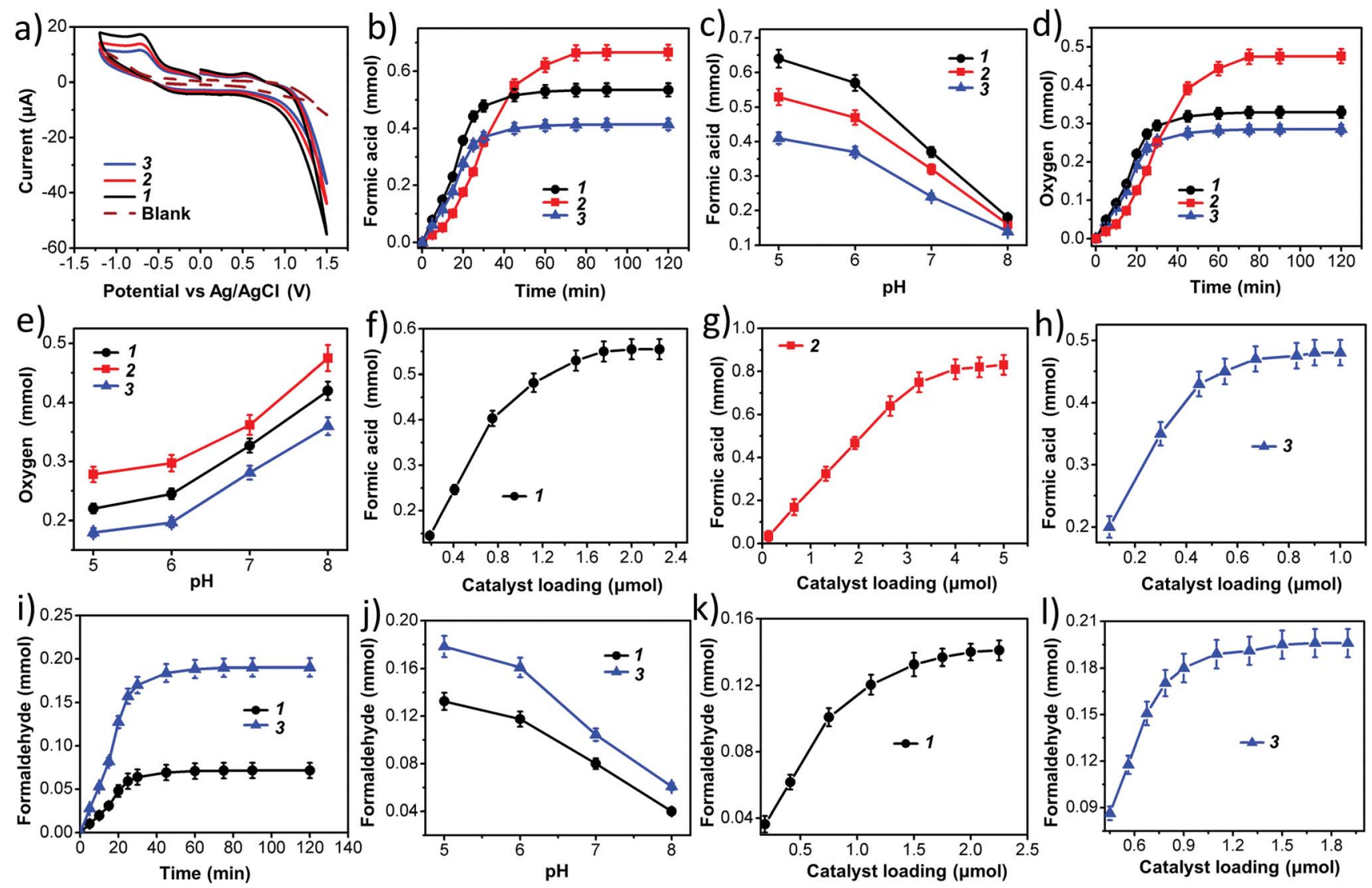

Fig. 6 (a) Cyclic voltammetry of the reaction product after $\mathrm{CO}_{2}$ reduction coupled with water oxidation, (b) time-dependent formic acid formation by photochemical carbon dioxide reduction using 1, 2, 3 as the catalyst at $\mathrm{pH} 5$, (c) pH-dependent formic acid formation, (d) timedependent evolution of oxygen at pH 5, (e) pH-dependent $\mathrm{O}_{2}$ formation, (f, g \& h) variation of catalyst $1-\left\{\mathrm{Mo}_{154}\right\}_{1165}, 2-\left\{\mathrm{Mn}_{6} \mathrm{P}_{3} \mathrm{~W}_{24}\right\}_{931}, 3-$ $\left\{\mathrm{MO}_{132}\right\}_{1064}$ on formic acid formation, respectively, (i) time-dependent generation of formaldehyde, catalyst 2 shows no formaldehyde generation, (j) pH variation with catalyst 1 and 3 to get maximum formaldehyde at $\mathrm{pH} 5$ for both cases, and (k) 8 (l) variation of catalyst loading on formaldehyde formation for 1 and 3 , respectively. 
Table 1 Calculation of the number of metal oxide cluster molecules per vesicle

\begin{tabular}{llll}
\hline Catalyst & $R(\mathrm{~nm})$ & $\sigma(\AA)$ & $\begin{array}{l}\text { Number of metal oxide } \\
\text { clusters present per vesicle of SOM }\end{array}$ \\
\hline $\mathrm{Mo}_{132} @ \mathrm{RGO}$ & 302 & 29.92 & 1064 \\
$\mathrm{Mn}_{6} \mathrm{P}_{3} \mathrm{~W}_{24}$ & 130 & 13.78 & 931
\end{tabular}

Then, we investigated the effect of the $\mathrm{pH}$ of the reaction medium on the photochemical $\mathrm{CO}_{2}$ reduction reaction as well as the photochemical water oxidation reaction. $\mathrm{CO}_{2}$ reduction increases with decreasing $\mathrm{pH}$ (Fig. $6 \mathrm{c}$ and $\mathrm{j}$ ) while water oxidation reaction is hindered (Fig. 6e). This can be explained by considering three different reaction equilibria (eqn (4)-(6)).

$$
\begin{gathered}
2 \mathrm{H}_{2} \mathrm{O} \rightarrow 4 \mathrm{H}^{+}+\mathrm{O}_{2}+4 \mathrm{e} \\
\mathrm{CO}_{2}+2 \mathrm{H}^{+}+2 \mathrm{e} \rightarrow \mathrm{HCOOH} \\
\mathrm{CO}_{2}+4 \mathrm{H}^{+}+4 \mathrm{e} \rightarrow 2 \mathrm{HCHO}
\end{gathered}
$$

As we know that carbon dioxide reduction is a proton coupled reaction and therefore, formation of the reduced product is always favored with increasing proton concentration in the reaction medium i.e. decreasing the $\mathrm{pH}$ of the reaction medium. On the other hand, the water oxidation reaction releases protons into the reaction medium and therefore, removal of protons from the reaction medium enhances the rate of water oxidation. Thus, with an increasing $\mathrm{pH}$ of the reaction medium, the rate of water oxidation increases.

Catalyst concentration dependent studies on the reactions follow the normal trend of heterogeneous catalyst kinetics. ${ }^{66}$ Initially the concentration of reduced product increases with the concentration of catalyst up to a certain limit of catalyst loading. Then, the rate of the increment of product formation decreases with catalyst loading and finally, the reaction becomes independent of catalyst concentration. This is due to the fact that such reactions are totally dependent on the active surface area of the catalyst, which does not change after a certain loading of the catalyst. We already mentioned that vesicle-like super-structures of oxometalates in the dispersion are actual active catalysts, therefore the active surface area is generally the surface area of a vesicle, which increases with increasing radius (i.e. hydrodynamic radius) of the vesicle. It is observed that after certain loading of catalyst, the hydrodynamic radius does not increase with the concentration of oxometalate as phase instabilities set in. Thus, after reaching a certain value, the active surface area remains constant, which is reflected in the nature of product concentration profile with catalyst loading (Fig. 6f-h, k and l).

\section{Calculation of the active catalyst concentration and thus, the TON of the reaction}

In the case of 1, 2, and 3, $116.7 \mu \mathrm{mol}, 40.6 \mu \mathrm{mol}$ and $205 \mu \mathrm{mol}$ formic acid was obtained, respectively with a loading of $0.15 \mu \mathrm{mol}$ catalyst in each case. The turnover numbers of the reaction per mole of the catalysts are 778, 270 and 1366 for 1, 2, and 3 , respectively. We have already mentioned that these oxometalates undergo self-assembly in a dispersion to form a vesicle-like SOM super-structure. ${ }^{\mathbf{4 3 , 4 4 , 6 2 , 6 7}}$ Therefore, the active catalyst in reaction medium is different to that found for the solid catalyst we have taken in the reaction. Also, due to the selfassembly active surface area of all the catalysts increasing when compared to the surface area of solid catalysts. We have calculated the active concentration of the catalysts, i.e., the number of catalyst molecules forming the SOM vesicle in the dispersion (Table 1).

Considering the effective concentration of the catalysts in the reaction, we calculated the effective turnover number of the catalysts. The results are summarized and tabulated in Table 2.

In the case of $\mathrm{Mo}_{154}$, the number of metal oxide cluster units present in a single SOM vesicle is $1165 .{ }^{62}$ Thus, we have calculated the number of metal oxide clusters present per SOM vesicle using eqn (7).

$$
\text { No. of metal oxide cluster unit }=\left(4 \pi R^{2}\right) /\left(72.006 \sigma^{2}\right) \times 60
$$

$R$ is the hydrodynamic radius of the SOM vesicle formed in the dispersion. $R$ is obtained using dynamic light scattering (DLS) analysis. $\sigma$ is the diameter of the isolated single cluster, taking the van der Waals radii of the constituent atoms.

We can now calculate the actual turnover number of this reaction, which is obtained dividing the concentration of product by the concentration of active catalyst vesicles in the dispersion (Table 2). We have performed each experiment five times, so an average yield out of those sets of experiments has been considered to calculate the turnover numbers. In this way the turnover numbers were found to be $0.9 \times 10^{6}, 0.25 \times 10^{6}$ and $1.4 \times 10^{6}$ for 1,2 , and 3 , respectively.

The water oxidation kinetics for all three catalysts are identical to the carbon dioxide reduction kinetics (Fig. 6d). This indicates that the water oxidation and carbon dioxide reduction reactions take place simultaneously. This also indicates an

Table 2 Calculation of the turnover number per mole of catalyst and the 'effective turnover number'

\begin{tabular}{llllllr}
\hline & $\begin{array}{l}\text { Amount of } \\
\text { solid catalyst } \\
(p)(\mu \mathrm{mol})\end{array}$ & $\begin{array}{l}\text { Number of catalyst } \\
\text { molecule formed } \\
\text { catalyst vesicle }(m)\end{array}$ & $\begin{array}{l}\text { Concentration of } \\
\text { catalyst vesicle in } \\
\text { dispersion }(q=p / m)(\mathrm{nmol})\end{array}$ & $\begin{array}{l}\text { Formic acid } \\
\text { formed in reaction } \\
(r)(\mu \mathrm{mol})\end{array}$ & $\begin{array}{l}\text { TON per } \\
\text { mole catalyst } \\
(s=r / p)\end{array}$ & $\begin{array}{l}\text { TON with respect to } \\
\text { concentration of catalyst } \\
\text { SOM vesicle }(t=r / q)\end{array}$ \\
\hline 1 & 0.15 & 1165 & 0.129 & 116.7 & & $\begin{array}{l}\text { TOF } \\
\left(\mathrm{s}^{-1}\right)\end{array}$ \\
2 & 0.15 & 931 & 0.161 & 40.6 & 278 & $0.9 \times 10^{6}$ \\
3 & 0.15 & 1064 & 0.140 & 205 & 1366 & $0.25 \times 10^{6}$ \\
$1.4 \times 10^{6}$ & 577
\end{tabular}


interesting fact that carbon dioxide reduction in this reaction is coupled with the water oxidation reaction. We will now check whether these two processes are indeed coupled.

On the coupling of the redox processes: the dependency of $\mathrm{CO}_{2}$ reduction on water oxidation

To check whether $\mathrm{CO}_{2}$ reduction depends on the water oxidation reaction, we have performed the photochemical $\mathrm{CO}_{2}$ reduction reaction in dry dimethyl formamide (DMF), keeping the other conditions unchanged. In this aprotic solvent, we observed that there is no reduction of $\mathrm{CO}_{2}$ (Fig. 7a and c) indicating that photochemical $\mathrm{CO}_{2}$ reduction may depend on the photochemical water oxidation reaction. To further prove the dependency, we then performed the reaction using different ratios of water and DMF. Upon gradually increasing the amount of water in the reaction mixture, we noticed a gradual increase in the amount of formic acid and evolved oxygen in the reaction system (Fig. 7b). We have also shown the increase in the generation of $\mathrm{HCOOH}$ and $\mathrm{O}_{2}$ by cyclic voltammetry (Fig. 7a). In the $\mathrm{CV}$, we see no peak at $-0.6 \mathrm{~V}$ in the absence of water, which indicates the absence of any reduced products of $\mathrm{CO}_{2}$ like $\mathrm{HCOOH}$ in the reaction medium. Upon gradually increasing the amount of water, there is an increase in the peak at $-0.6 \mathrm{~V}$ along with a simultaneous increase in the current at $1.2 \mathrm{~V}$, which indicates water oxidation and the production of $\mathrm{O}_{2}$. A similar trend is seen in the amount of $\mathrm{HCOOH}$ and $\mathrm{O}_{2}$ formed. For instance, the production of $\mathrm{HCOOH}$ increases upon increasing the amount of water. The above results confirm that photochemical $\mathrm{CO}_{2}$ reduction depends on photochemical water oxidation and that these processes are coupled.

\section{On the reaction pathway}

Now, we can delineate the likely reaction pathway. To do so we first identified the essential components of the reaction: 1 . Light: without light the reaction does not take place and 2 . Water: we have already seen that without water there is no $\mathrm{CO}_{2}$ reduction. All these demonstrate that the catalytic reaction has three crucial components: light, water and $\mathrm{CO}_{2}$.
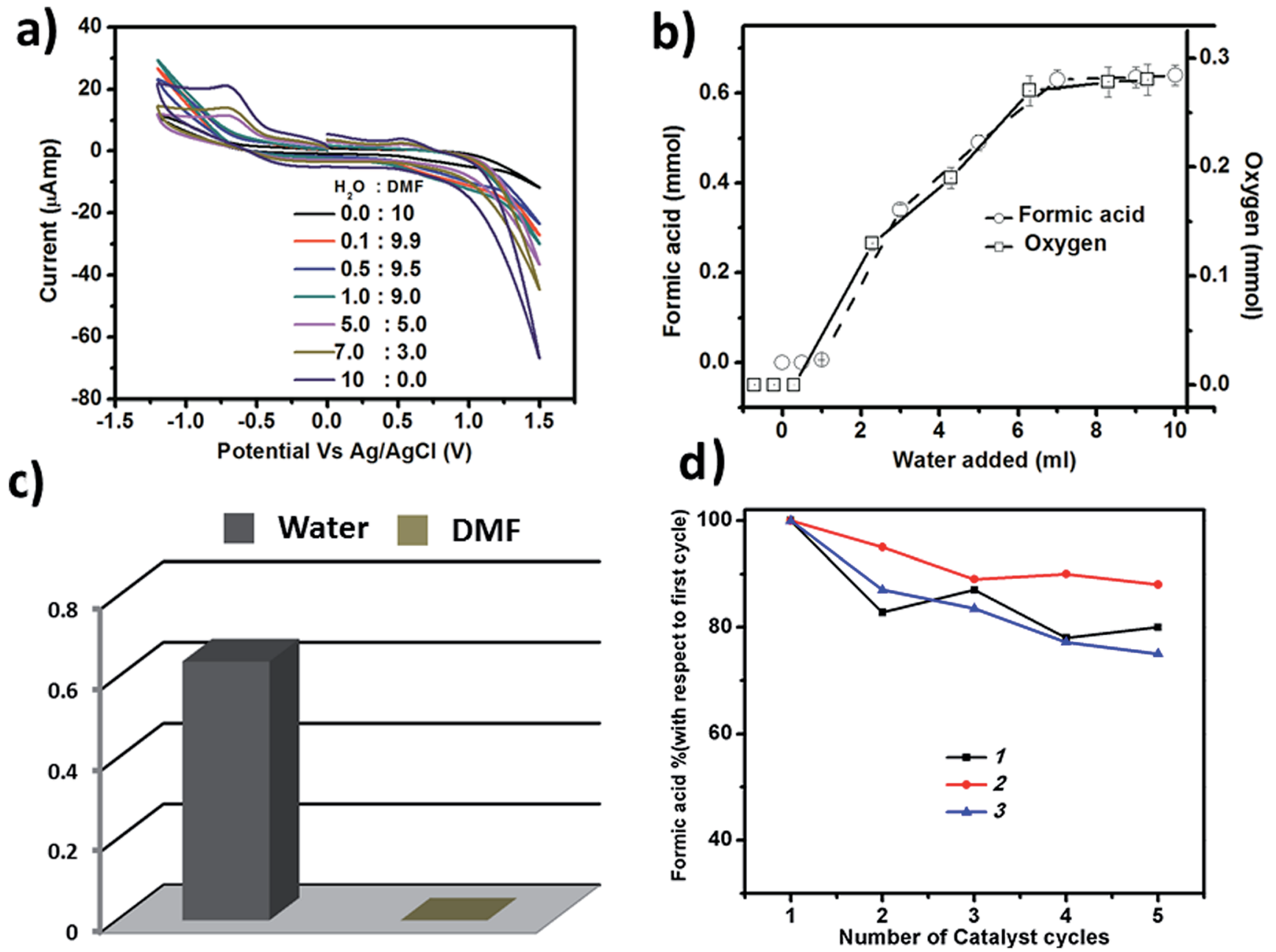

Fig. 7 (a) The CV of the solution after the reaction with a gradual increase in the water amount, (b) the increase in the amount of formic acid and oxygen with an increase in the water amount in reaction system, (c) the amount of formic acid formation in $10 \mathrm{~mL}$ of water and $10 \mathrm{~mL}$ of DMF, showing no formic acid formation in DMF, and (d) the reusability of all three catalysts shown up to 5 cycles of the reaction in terms of the yield of formic acid. 
We now sketch a pathway for the reaction. We speculate that the initial clusters go to their excited state upon irradiation with UV-light. Clusters in the excited state generate excitons that in turn create holes $\left(\mathrm{h}^{+}\right)$and electrons $\left(\mathrm{e}^{-}\right)$in pairs. Now, the generated holes $\left(\mathrm{h}^{+} \mathrm{s}\right)$ oxidize $\mathrm{H}_{2} \mathrm{O}$ to produce oxygen and release electrons and protons in the reaction. ${ }^{68}$ Proton coupled reduction of $\mathrm{CO}_{2}$ to form $\mathrm{HCOOH} / \mathrm{HCHO}$ takes place by subsequent transfer of the electrons and protons released during water oxidation. Thus, in this photochemical $\mathrm{CO}_{2}$ reduction coupled with water oxidation water acts as the only electron source in the reduction reaction. After each cycle the catalyst goes back to its initial state and gets re-excited by light again and the catalytic cycle continues.

Now, to show the actual catalyst in the reaction medium, we performed the photochemical $\mathrm{CO}_{2}$ reduction, keeping the other conditions the same using precursor constituents of 1, 2 and 3. No reaction was observed with those precursor constituents (Table S1 in the ESI $\dagger$ ). It implies that the vesicle-like SOM superstructures composed of giant metal oxide clusters are only responsible for the photochemical $\mathrm{CO}_{2}$ reduction reaction in water. All these results are tabulated in Table $\mathrm{S} 2 . \dagger$

\section{The stability of catalysts 1,2 and 3}

The catalysts are stable up to many cycles of the reaction. This is shown by Raman and infrared spectroscopy (shown in Fig. 8 \&
$\mathrm{S} 13-\mathrm{S} 15 \dagger)$. For instance, we have reused the catalysts for five cycles and have seen a maximum $25 \%$ decrease in the yield for the production of $\mathrm{HCOOH}$, in the case of catalyst 3. In the case of 1 , the decrease is $20 \%$ while 2 exhibits the maximum reusability with a decrease in yield of formic acid of only $12 \%$ after five cycles (Fig. 7d). Thus, all the catalysts can be reused further to catalyse the same reaction.

\section{On the photochemical activity of the catalysts}

To show that the catalysts are photochemically active under the reaction condition, we have performed dye degradation studies using 1, 2 and 3. We have used methyl orange for 1, methylene blue for 2 , while perylene tetracarboxylate was used in the case of 3, to avoid the absorption maxima overlapping with the catalysts. Methyl orange shows an absorption maxima at $455 \mathrm{~nm}$, methylene blue shows at $560 \mathrm{~nm}$ and perylene tetracarboxylate has three bands at 385, 410 and $415 \mathrm{~nm}$. The UV spectra of the dye with the catalysts show that all of the catalysts can degrade their corresponding dyes upon irradiation as evident from the decreasing intensity of the UV-Vis maxima of the dyes with time (Fig. 9).

Here, it is worth mentioning that the SOM-type catalysts provide better catalytic activity than the conventional catalysts owing to the simultaneous excitation of millions of photoactive
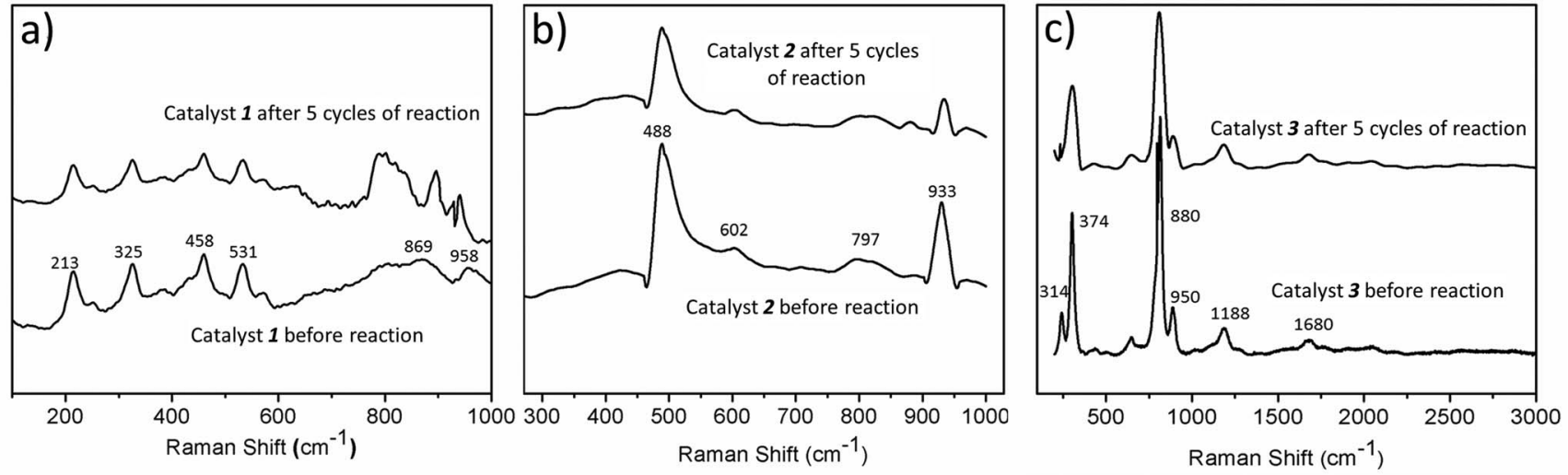

Fig. 8 The stability of all three catalysts after the reaction, as shown by Raman spectroscopy.
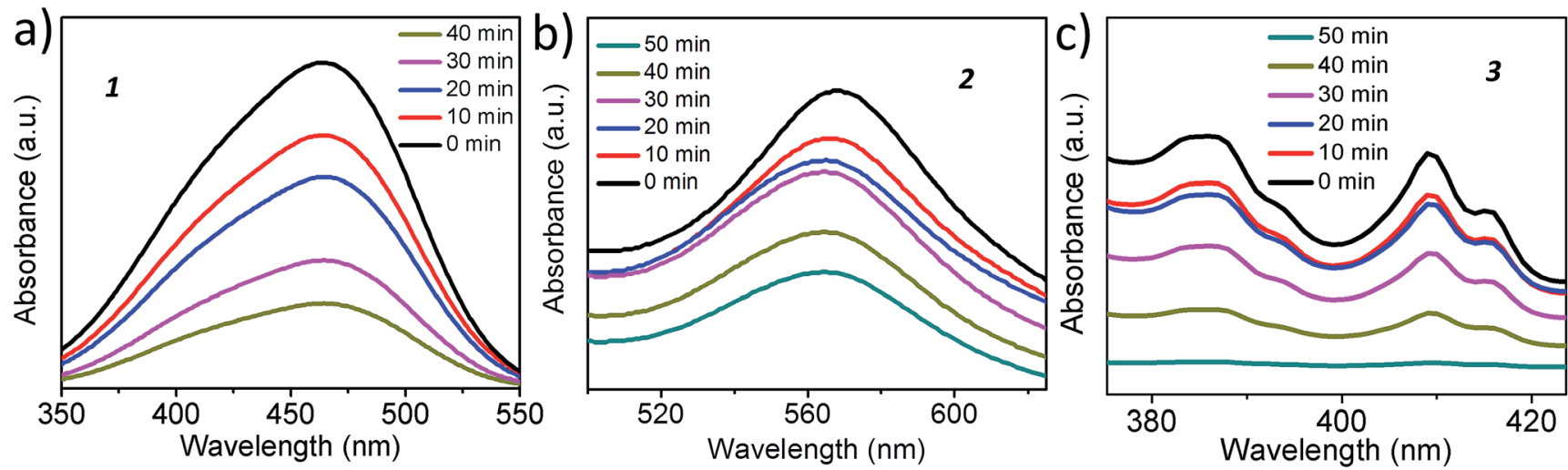

Fig. 9 Dye degradation studies of catalyst 1 using methyl orange, 2 using methyl blue and 3 using perylene tetracarboxylate. A gradual decrease in the intensity of the dyes with the irradiated catalysts proves the photoactivity of the catalysts. 
clusters in the catalyst vesicles under photochemical conditions due to the high number density of the molecules in the vesicles, which is usually not the case in conventional semiconductors used as photocatalysts.

\section{Experimental section}

\section{Materials and reagents}

All the materials were purchased from commercially available sources and used without further purification. All glassware was first boiled in an acid bath then washed with water and finally cleaned with acetone. They were dried in hot air oven overnight. We used doubly distilled deionized water in all the experiments.

\section{Synthesis of $\mathrm{Mo}_{154}$}

$\left(\mathrm{Na}_{15}\left[\mathrm{Mo}^{V I}{ }_{126} \mathrm{Mo}^{V}{ }_{28} \mathrm{O}_{462} \mathrm{H}_{14}\left(\mathrm{H}_{2} \mathrm{O}\right)_{70}\right]_{0.5}\left[\mathrm{Mo}^{V I}{ }_{124} \mathrm{Mo}_{28}{ }_{28} \mathrm{O}_{457} \mathrm{H}_{14}\right.\right.$ $\left.\left(\mathrm{H}_{2} \mathrm{O}\right)_{68}\right]_{0.5} \cdot$ hydrate). To a solution of $\mathrm{Na}_{2} \mathrm{MoO}_{4} \cdot 2 \mathrm{H}_{2} \mathrm{O}(3.0 \mathrm{~g}, 12.4$ $\mathrm{mmol})$ in $10 \mathrm{~mL}$ of water, freshly powdered $\mathrm{Na}_{2} \mathrm{~S}_{2} \mathrm{O}_{4}(0.2 \mathrm{~g}, 1.15$ $\mathrm{mmol}$ ) was added (light yellow coloration). Immediately afterwards, under continuous stirring, $30 \mathrm{~mL}$ of hydrochloric acid (1 M) was rushed into the solution (color changes to deep blue). The solution was stirred in an open $100 \mathrm{~mL}$ Erlenmeyer flask for further $10 \mathrm{~min}$ and then stored undisturbed in a closed flask at $20{ }^{\circ} \mathrm{C}$ for 3 days. The precipitated blue crystals were removed by filtration, washed quickly with a small amount of cold water and dried at room temperature over $\mathrm{CaCl}_{2}$. Yield: $0.7 \mathrm{~g}(13.18 \%$ based on Mo).

Synthesis and characterization of $\mathrm{Na}_{17}\left[\mathrm{Mn}_{6} \mathbf{P}_{3} \mathbf{W}_{24} \mathrm{O}_{\mathbf{9 4}}\left(\mathrm{H}_{2} \mathrm{O}\right)_{2}\right]$. $\mathrm{Na}_{2} \mathrm{WO}_{4} \cdot 2 \mathrm{H}_{2} \mathrm{O}(11.873 \mathrm{~g}, 0.036 \mathrm{~mol}), \mathrm{Na}_{2} \mathrm{HPO}_{4} \cdot 7 \mathrm{H}_{2} \mathrm{O}(1.073 \mathrm{~g}$, $0.004 \mathrm{~mol})$ and $\mathrm{Mn}(\mathrm{OAc})_{2} \cdot 4 \mathrm{H}_{2} \mathrm{O}(1.96 \mathrm{~g}, 0.008 \mathrm{~mol})$ were mixed in $30 \mathrm{~mL}$ of water. The color of the solution turned light yellow and then, the reaction mixture was heated to $100{ }^{\circ} \mathrm{C}$ for $3 \mathrm{~h}$. After heating, the color of the reaction mixture turned dark yellow. The reaction mixture was cooled to room temperature and then, the $\mathrm{pH}$ was adjusted to 6 . The reaction mixture was then saturated with excess $\mathrm{NaCl}$ and finally filtered off. A clear yellow solution was obtained, which was stored in an open Erlenmeyer-flask for crystallization. After 1 week pale yellow crystals were obtained. The crystals were filtered, washed with water and dried in vacuum overnight. Yield: $27 \%$ (based on Mn). Thermogravimetric estimation shows 43 water molecules of hydration and agrees well with that of the unit cell volume (Fig. S2 $\dagger$ ). Characteristic FT-IR peaks $\left(\mathrm{cm}^{-1}\right): 1617,1416,1065,932,730,480$. EAS spectroscopy: $\lambda_{\max }=250 \mathrm{~nm}$. The cif structure of the cluster is available on internet vide CCDC number 1057222.

\section{Synthesis of Mo ${ }_{132} @ R G O$}

Synthesis of $\mathrm{Mo}_{132}$. The cluster was prepared according to a literature procedure. ${ }^{69} \mathrm{~N}_{2} \mathrm{H}_{4} \cdot \mathrm{H}_{2} \mathrm{SO}_{4}(0.8 \mathrm{~g}, 6.1 \mathrm{mmol})$ was added to a solution of $\left(\mathrm{NH}_{4}\right)_{6} \mathrm{Mo}_{7} \mathrm{O}_{24} \cdot 4 \mathrm{H}_{2} \mathrm{O}(5.6 \mathrm{~g}, 4.5 \mathrm{mmol})$ and $\mathrm{CH}_{3} \mathrm{COONH}_{4}(12.5 \mathrm{~g}, 162.2 \mathrm{mmol})$ in $\mathrm{H}_{2} \mathrm{O}(250 \mathrm{~mL})$. The solution was then stirred for $10 \mathrm{~min}$ (color change to blue green) and $50 \% \mathrm{CH}_{3} \mathrm{COOH}(83.0 \mathrm{~mL})$ was subsequently added. The reaction solution, now green, was stored in an open $500 \mathrm{~mL}$ Erlenmeyer flask at $20{ }^{\circ} \mathrm{C}$ without further stirring (fume hood; slow color change to dark brown). After 4 days, the precipitated red-brown crystals of were filtered off over a glass fritt (D2), washed with $90 \%$ ethanol, ethanol and diethyl ether, and finally dried in air. Yield: $3.3 \mathrm{~g}$ ( $52 \%$ based on molybdate). Raman spectrocopy confirmed the structure of the prepared $\mathrm{Mo}_{132}$.

Synthesis of $R G O$. Firstly, graphene oxide (GO) was prepared via the modified Hummers' method. ${ }^{70}$ Typically, $50 \mathrm{~g}$ of $\mathrm{H}_{2} \mathrm{SO}_{4}$ $(98 \%)$ and $2 \mathrm{~g}$ of graphite were placed in a reactor cooled to $0{ }^{\circ} \mathrm{C}$ using an ice-water bath. After stirring the suspension for $30 \mathrm{~min}, 0.3 \mathrm{~g}$ of $\mathrm{KMnO}_{4}$ was added in small portions keeping the temperature in the reactor less than $10{ }^{\circ} \mathrm{C}$ using an ice-water bath. After stirring the mixture for 30 minutes, $6 \mathrm{~g}$ of $\mathrm{KMnO}_{4}$ was further added to the suspension gradually. Then, the reactor was heated for 30 minutes to keep the temperature constant at approximately $35^{\circ} \mathrm{C}$. As the reaction progressed, the suspension became pasty and brown in color. At the end of this $30 \mathrm{~min}$ period, $90 \mathrm{~mL}$ of water was slowly stirred into the paste to prevent violent effervescence, causing an increase in temperature from (90 to 95 ) ${ }^{\circ} \mathrm{C}$. The diluted suspension, now brown in color, was maintained at this temperature for $15 \mathrm{~min}$. The suspension was then further treated with a mixture of $7 \mathrm{~mL}$ of hydrogen peroxide (30\%) and $53 \mathrm{~mL}$ of water to reduce the residual permanganate and $\mathrm{MnO}_{2}$ to soluble $\mathrm{MnSO}_{4}$. The suspension was filtered and washed with distilled water three times and the solids were collected by filtration and dried at 45 ${ }^{\circ} \mathrm{C}$. Graphene was prepared via a hydrothermal process using a basic solution. Generally, $2 \mathrm{~g}$ of GO was mixed in $80 \mathrm{~mL}$ of ultrapure water and the mixture was stirred for $4 \mathrm{~h}$. The suspension was then ultrasonically treated for $1 \mathrm{~h}$. A concentrated ammonia solution (37 wt\%) was used to adjust the suspension to $\mathrm{pH} 10$. The suspension was kept stirred overnight with a cover. Then, the mixture was transferred into a Teflonlined autoclave $(120 \mathrm{~mL})$ and treated at $453 \mathrm{~K}$ for $18 \mathrm{~h}$. The precipitate was washed three times with ultrapure water/ ethanol. After filtration, the chemically reduced graphene oxide was dried at $353 \mathrm{~K}$.

Preparation protocol and stability of the $\mathrm{Mo}_{132} @ R G O$ composite. We have added a fixed ratio of $\mathrm{RGO}$ and $\mathrm{Mo}_{132}$ and kept it for 1 week in the dark after sonication for $4 \mathrm{~h}$. We have seen that only a $\mathrm{RGO} / \mathrm{Mo}_{132}$ ratio of $1.2: 1$ provides a stable composite for which a dispersion is stable, even for months. So, this ratio was taken for characterization and the photochemical experiments.

\section{Characterization techniques}

Fourier transform infra-red spectroscopy (FT-IR). FTIR spectroscopy of catalysts 1 and 2 was performed using $\mathrm{KBr}$ discs. Initially a pellet was prepared from a mixture of $\mathrm{KBr}$ and $3 \mathrm{mg}$ of $\mathbf{1}$ or 2 . The FTIR spectrum was recorded using a Perkin Elmer Spectrum RX1 spectrophotometer with FTIR facility in the range $2000-400 \mathrm{~cm}^{-1}$ for $1 \& 2$ and $3000-500$ for 3 . The horizontal attenuated total internal reflectance (HATR) spectrum of catalyst $\mathbf{3}$ and also for $\mathbf{1}$ and $\mathbf{2}$ were also acquired for the liquid samples. In that case we placed $1 \mathrm{~mL}$ of the sample on a zinc selenite palate and the IR spectrum was recorded within a range of $2000-600 \mathrm{~cm}^{-1}$. The spectrum obtained in this process is quite different from that obtained using the FT-IR method. We observe broad peaks rather than sharp peaks, which are obtained in the FT-IR spectrum. This is due to the 
presence of water in the sample and the low concentration of the sample.

Electronic absorption spectroscopy (EAS). Very dilute solutions of 1-3 were taken in a quartz cuvette and the electronic absorption spectrum were recorded on a U-4100 spectrophotometer (Liquid) within the desired range.

Cyclic voltammetry (CV). A PAR model 273 potentiostat was used for the CV experiments. A platinum wire auxiliary electrode, a glassy carbon working electrode with surface area of $0.002826 \mathrm{~cm}^{2}$ and an aqueous $\mathrm{Ag} / \mathrm{Ag}^{+}$reference electrode, which was filled with saturated $\mathrm{KCl}$ solution, were used in a three electrode configuration. The scan rate was $0.5 \mathrm{~V} \mathrm{~s}^{-1}$. The $\mathrm{CV}$ spectrum was recorded in the range of $-1.2 \mathrm{~V}$ to $+1.3 \mathrm{~V}$. The blank refers to the amount of oxygen present in distilled water in our mentioned reaction conditions. The $\mathrm{pH}$ of the medium was 7. 0.1 M KCl solution was used as the supporting electrolyte in all the experiments. All measurements were performed at $298 \mathrm{~K}$ under an inert atmosphere.

Raman spectroscopy. A LABRAM HR800 Raman spectrometer was employed using the $633 \mathrm{~nm}$ line of a He-Ne ion laser $(\lambda=633 \mathrm{~nm})$ as the excitation source to analyze the sample.

Resonance Raman spectroscopy. A Bruker RFS27 spectrometer was employed using the $1064 \mathrm{~nm}$ line as an excitation source.

Matrix-assisted laser desorption ionization-mass spectrometry (MALDI-MS). Matrix-assisted laser desorption ionization time-of-flight (MALDI-TOF) mass spectrometry was carried out on a Bruker ultrafleXtreme ${ }^{\mathrm{TM}}$ instrument equipped with a smart beam-II laser in the reflector mode and $22 \mathrm{kV}$ acceleration voltage. 2,5-Dihydroxybenzoic acid (DHB, Bruker) was used as the matrix.

Transmission electron microscopy (TEM). TEM (transmission electron microscopy) images are taken with a JEOL JEM 2010 electron microscope.

Dynamic light scattering (DLS). DLS experiments were performed using a Malvern Zetasizer instrument equipped with a $633 \mathrm{~nm}$ laser.

Scanning electron microscopy-energy-dispersive X-ray spectroscopy (SEM-EDS). The images were recorded with a SUPRA 55 VP-41-32 scanning electron microscope and analyzed using the Smart-SEM version 5.05 Zeiss software. The SEM sample was prepared by drop casting a very dilute dispersion onto a silicon wafer and drying in a dust free area.

Single crystal X-ray diffraction (SCXRD). A pale yellow crystal of 2 was selected on a SuperNova, Dual, $\mathrm{Cu}$ at zero, Eos diffractometer. The crystal was kept at $100.00(12) \mathrm{K}$ during data collection. Using Olex2, the structure was solved with the superflip structure solution program using charge flipping and refined with the ShelXL refinement package using least squares minimization. Single intensity data was collected with graphitemonochromatic Mo-K $\alpha$ radiation $(\mu=20.898)$. Among the 23969 unique reflections $\left(R_{\mathrm{int}}=0.0505,2 \theta_{\max }=50.06\right) 18947$ were considered to be observed with $(I>2 \sigma(I))$. The final cycle of refinement, including the atomic coordinates, anisotropic thermal parameters, ( $\mathrm{W}, \mathrm{P}$, and $\mathrm{Ni}$ atoms), and isotropic thermal parameters ( $\mathrm{Na}$ and $\mathrm{O}$ atoms), converged at $R=0.0869$ and $R_{\mathrm{w}}=0.221(I>2 \sigma(I))$ In the final difference map the highest peak was 7.83 e $\AA^{-3}$ and the deepest hole -10.784 e $\AA^{-3}$. The unique crystal data number is CCDC 1057222.

Electron paramagnetic resonance spectroscopy (EPR). A very well ground sample was poured into a thin EPR tube and the EPR spectrum was measured at room temperature on a Bruker A 300 electron paramagnetic resonance instrument in the range of 1350 Gauss to 5350 Gauss.

Thermogravimetric analysis (TGA). TGA was performed using a Shimadzu DTG-60 thermal analyzer system at a heating rate of $10{ }^{\circ} \mathrm{C} \mathrm{min}$ m $^{-1}$ to $500{ }^{\circ} \mathrm{C}$ in a dried air atmosphere and the air flow rate was $30 \mathrm{~mL} \mathrm{~min}^{-1}$. The sample was loaded on an alumina pan.

${ }^{\mathbf{1}}$ H NMR spectroscopy. ${ }^{1} \mathrm{H}$ NMR spectroscopy was performed using a Bruker Avance $500 \mathrm{MHz}$ spectrometer.

General reaction procedure for the photo-catalytic $\mathrm{CO}_{2}$ reduction and water oxidation reactions. The photo-catalytic carbon dioxide reduction reactions were performed as follows: a desired amount of catalyst (1-3) was taken in $10 \mathrm{~mL}$ of degassed double distilled water. The reaction mixtures were then sealed and $\mathrm{CO}_{2}$ gas was purged for $2 \mathrm{~h}$. The reaction mixtures were kept in a photo-reactor under UV-light (energy density $19 \mathrm{~mW} \mathrm{~cm} \mathrm{~cm}^{-2}$ lamp, $\lambda=373 \mathrm{~nm}$ ) for different time intervals. Then, $20 \mu \mathrm{L}$ of the reaction mixture was taken out from the aliquot and diluted to $10 \mathrm{~mL}$ with doubly distilled water. The aliquots were used directly for HPLC to quantify the liquid products with an external standard of $0.1 \mathrm{M}$ formic acid and formaldehyde solution. Furthermore, a Clark type electrode was used to measure the evolved oxygen due to water oxidation. All of the results of these experiments are recorded in Fig. 6. For MALDI-MS experiment we co-crystalized the product with an HCCA matrix prior to recording the MS data. From all the mass measurement techniques we obtained the molecular ion peak of formic acid.

Next we performed CV experiments with the reaction mass using $\mathrm{KCl}$ as an electrolyte within a potential range of $+1.5 \mathrm{~V}$ to $-1.2 \mathrm{~V}$ with respect to the $\mathrm{Ag} / \mathrm{AgCl}$ reference electrode in a standard 3-electrode system. We obtained a peak around $-0.6 \mathrm{~V}$, which is indicative of the formation of formic acid from carbon dioxide. To further prove the formation of formic acid in the reaction medium we performed a coupling reaction with the resulting reaction solution. An excess solution of aniline $(100 \mu \mathrm{L})$ in $2 \mathrm{~mL}$ of acetonitrile was added to the reaction mixture and $20 \mathrm{mg}$ HATU (1-[bis(dimethylamino) methylene]-1H-1,2,3-triazolo[4,5-b]pyridinium 3-oxid hexafluorophosphate) was added as a coupling agent. The reaction mixture was stirred for $1 \mathrm{~h}$ at room temperature resulting in the formation of the amide in the reaction medium. The organic components were extracted with EtOAc $(3 \times 10 \mathrm{~mL})$ and then, the EtOAc was removed in vacuo. Then, the solid mass was further dissolved in acetonitrile to perform GC-MS and MALDI-MS following the above mentioned procedure. After purification we further characterized the amide using ${ }^{1} \mathrm{H}$ NMR spectroscopy.

High performance liquid chromatography (HPLC). All the reaction samples were monitored by an HITACHI-HPLC system equipped with binary 2130 pumps, a manual sampler and 2490 refractive index detector, maintained at $50{ }^{\circ} \mathrm{C}$. The 
products were separated on a sugar ion-exclusion column $(250 \times 4.8 \mathrm{~mm})$ maintained at $60^{\circ} \mathrm{C}$ using water as the mobile phase at a $0.8 \mathrm{~mL} \min ^{-1}$ flow rate. The HPLC system was controlled and processed by Inkarp software. A standard formic acid and formaldehyde solution was prepared and calibrated. Each product sample was diluted with a known volume of milli-Q water before analysis to prevent overloading the column. All experiments were carried out five times and the average values were reported within a standard deviation of $<5.0 \%$.

Gas chromatography-mass spectrometry (GC-MS). The products were identified and analyzed using a GCMS-QP-2010 Ultra $\left(\mathrm{M} \mathrm{s}^{-1}\right.$. Shimadzu Instruments, Japan) equipped with a HB-5 capillary column $(20 \mathrm{~m} \times 0.18 \mathrm{~mm})$ supplied by $\mathrm{M} \mathrm{s}^{-1}$. J\&W Scientific, USA.

pH dependent study. This experiment was performed following a previous procedure using different buffer solutions in the range of pH 5 to 8 for all the catalysts. Measurement of the $\mathrm{HCOOH}$ and oxygen was carried out using a similar method to that mentioned earlier.

\section{Conclusions}

We have shown a scalable pathway for photochemical carbon dioxide reduction coupled with water oxidation using three different SOM type heterogeneous mixed valent metal oxide based clusters with the highest turnover numbers recorded till date ( $c a .1366$ per mole, effectively $1.4 \times 10^{6}$ ). All these metal oxide based clusters are photoactive and therefore, there is no need for any external photosensitizer in the reaction medium. Here water serves as an electron source and when coupled with carbon dioxide reduction, water oxidation obviates the need of any external sacrificial electron donor. Such a successful coupling enabled us to execute the simultaneous reduction of $\mathrm{CO}_{2}$ to $\mathrm{HCOOH} / \mathrm{HCHO}$ and oxidation of water to oxygen achieving an effective turnover number as high as $1.4 \times 10^{6}$. Thus, in short we have developed a fast, scalable and efficient carbon dioxide reduction model system where water oxidation provides electrons to reduce carbon dioxide. The possibility of adding a visible light sensitizer to make this system operate in sunlight does not escape our attention. The end product formic acid can be used directly in fuel cells providing green and clean energy.

\section{Author's contribution}

SD, SB and TB contributed equally to this work. SR proposed, initiated and coordinated the project, as well as wrote the paper.

\section{Acknowledgements}

SR gratefully acknowledges the grants obtained from IISERKolkata, India, DST-fast track and BRNS-DAE. SD and TB acknowledge IISER-K; SB and SB (Barman) acknowledge UGC and RP acknowledges DST for fellowship. This paper is dedicated to Prof. Achim Müller.

\section{Notes and references}

1 S. Lin, C. S. Diercks, Y.-B. Zhang, N. Kornienko, E. M. Nichols, Y. Zhao, A. R. Paris, D. Kim, P. Yang, O. M. Yaghi and C. J. Chang, Science, 2015, 349, 1208-1213. 2 D. G. Nocera, Acc. Chem. Res., 2012, 45, 767-776.

3 J. Collin and J. Sauvage, Coord. Chem. Rev., 1989, 93, 245-268.

4 C. Costentin, M. Robert and J.-M. Savéant, Chem. Soc. Rev., 2013, 42, 2423-2436.

5 J. Graetz, Chem. Soc. Rev., 2009, 38, 73-82.

6 M. Halmann, Nature, 1978, 275, 115-116.

7 T. Sakakura, J.-C. Choi and H. Yasuda, Chem. Rev., 2007, 107, 2365-2387.

8 A. J. Morris, G. J. Meyer and E. Fujita, Acc. Chem. Res., 2009, 42, 1983-1994.

9 R. D. Richardson, E. J. Holland and B. K. Carpenter, Nat. Chem., 2011, 3, 301-303.

10 Y. Oh and X. Hu, Chem. Soc. Rev., 2013, 42, 2253-2261.

11 T. Zhang and W. Lin, Chem. Soc. Rev., 2014, 43, 5982-5993.

12 J. Michl, Nat. Chem., 2011, 3, 268-269.

13 E. de Smit, F. M. de Groot, R. Blume, M. Hävecker, A. KnopGericke and B. M. Weckhuysen, Phys. Chem. Chem. Phys., 2010, 12, 667-680.

14 J. K. Hurst, Science, 2010, 328, 315-316.

15 Q. Yin, J. M. Tan, C. Besson, Y. V. Geletii, D. G. Musaev, A. E. Kuznetsov, Z. Luo, K. I. Hardcastle and C. L. Hill, Science, 2010, 328, 342-345.

16 W. Rüttinger and G. C. Dismukes, Chem. Rev., 1997, 97, 1-24. 17 M. Yagi and M. Kaneko, Chem. Rev., 2001, 101, 21-36.

18 R. Zong and R. P. Thummel, J. Am. Chem. Soc., 2005, 127, 12802-12803.

19 R. D. L. Smith, M. S. Prévot, R. D. Fagan, Z. Zhang, P. A. Sedach, M. K. J. Siu, S. Trudel and C. P. Berlinguette, Science, 2013, 340, 60-63.

$20 \mathrm{~S} . \mathrm{Hu}, \mathrm{M}$. R. Shaner, J. A. Beardslee, M. Lichterman, B. S. Brunschwig and N. S. Lewis, Science, 2014, 344, 10051009.

21 J. L. Fillol, Z. Codolà, I. Garcia-Bosch, L. Gómez, J. J. Pla and M. Costas, Nat. Chem., 2011, 3, 807-813.

22 L. Duan, F. Bozoglian, S. Mandal, B. Stewart, T. Privalov, A. Llobet and L. Sun, Nat. Chem., 2012, 4, 418-423.

23 J. Hawecker, J.-M. Lehn and R. Ziessel, J. Chem. Soc., Chem. Commun., 1984, 328-330.

24 M. Beley, J.-P. Collin, R. Ruppert and J.-P. Sauvage, J. Chem. Soc., Chem. Commun., 1984, 1315-1316.

25 B. J. Fisher and R. Eisenberg, J.Am. Chem. Soc., 1980, 102, 7361-7363.

26 H. J. Lewerenz and L. Peter, Photoelectrochemical Water Splitting: Materials, Processes and Architectures, Royal Society of Chemistry, 2013.

27 M. Bourrez, M. Orio, F. Molton, H. Vezin, C. Duboc, A. Deronzier and S. Chardon-Noblat, Angew. Chem., Int. Ed., 2014, 53, 240-243.

28 Z. Chen, C. Chen, D. R. Weinberg, P. Kang, J. J. Concepcion, D. P. Harrison, M. S. Brookhart and T. J. Meyer, Chem. Commun., 2011, 47, 12607-12609. 
29 C. L. Anfuso, R. C. Snoeberger, A. M. Ricks, W. Liu, D. Xiao, V. S. Batista and T. Lian, J. Am. Chem. Soc., 2011, 133, 69226925.

30 B. D. Steffey, A. Miedaner, M. L. Maciejewski-Farmer, P. R. Bernatis, A. M. Herring, V. S. Allured, V. Carperos and D. L. Dubois, Organometallics, 1994, 13, 4844-4855.

31 M. Erlandsson, V. R. Landaeta, L. Gonsalvi, M. Peruzzini, A. D. Phillips, P. J. Dyson and G. Laurenczy, Eur. J. Inorg. Chem., 2008, 2008, 620-627.

32 C. Das Neves Gomes, E. Blondiaux, P. Thuéry and T. Cantat, Chem.-Eur. J., 2014, 20, 7098-7106.

33 J. Zhao, X. Wang, Z. Xu and J. S. Loo, J. Mater. Chem. A, 2014, 2, 15228-15233.

34 M. C. Hsieh, G. C. Wu, W. G. Liu, W. A. Goddard and C. M. Yang, Angew. Chem., 2014, 126, 14440-14444.

35 K. Iizuka, T. Wato, Y. Miseki, K. Saito and A. Kudo, J. Am. Chem. Soc., 2011, 133, 20863-20868.

36 P. Kang, Z. Chen, A. Nayak, S. Zhang and T. J. Meyer, Energy Environ. Sci., 2014, 7, 4007-4012.

37 R. K. Hocking, R. Brimblecombe, L.-Y. Chang, A. Singh, M. H. Cheah, C. Glover, W. H. Casey and L. Spiccia, Nat. Chem., 2011, 3, 461-466.

38 D. M. Robinson, Y. B. Go, M. Mui, G. Gardner, Z. Zhang, D. Mastrogiovanni, E. Garfunkel, J. Li, M. Greenblatt and G. C. Dismukes, J. Am. Chem. Soc., 2013, 135, 3494-3501.

39 Y. Gorlin and T. F. Jaramillo, J. Am. Chem. Soc., 2010, 132, 13612-13614.

40 F. Jiao and H. Frei, Energy Environ. Sci., 2010, 3, 1018-1027. 41 N. A. Vante, W. Jaegermann, H. Tributsch, W. Hoenle and K. Yvon, J. Am. Chem. Soc., 1987, 109, 3251-3257.

42 J. Suntivich, H. A. Gasteiger, N. Yabuuchi, H. Nakanishi, J. B. Goodenough and Y. Shao-Horn, Nat. Chem., 2011, 3, 546-550.

43 S. Roy, CrystEngComm, 2014, 16, 4667-4676.

44 S. Roy, Comments Inorg. Chem., 2011, 32, 113-126.

45 S. Das, S. Kumar, A. Mallick and S. Roy, J. Mol. Eng. Mater., 2015, 03, 1540008.

46 A. Mallick, D. Lai and S. Roy, New J. Chem., 2016, 40, 10571062.

47 S. Roy, H. J. D. Meeldijk, A. V. Petukhov, M. Versluijs and F. Soulimani, Dalton Trans., 2008, 2861-2865, DOI: 10.1039/b800680f.

48 S. Roy, L. C. A. M. Bossers, H. J. D. Meeldijk, B. W. M. Kuipers and W. K. Kegel, Langmuir, 2008, 24, 666-669.
49 A. Müller and S. Roy, Eur. J. Inorg. Chem., 2005, 2005, 35613570 .

50 S. Biswas and S. Roy, Journal of Materials NanoScience, 2014, 1, 6.

51 S. Das, P. Thomas and S. Roy, Eur. J. Inorg. Chem., 2014, 2014, 4551-4557.

52 P. Thomas, C. Pei, B. Roy, S. Ghosh, S. Das, A. Banerjee, T. Ben, S. Qiu and S. Roy, J. Mater. Chem. A, 2015, 3, 14311441.

53 B. Roy, M. Arya, P. Thomas, J. K. Jürgschat, K. Venkata Rao, A. Banerjee, C. Malla Reddy and S. Roy, Langmuir, 2013, 29, 14733-14742.

54 K. Das and S. Roy, Chem.-Asian J., 2015, 10, 1884-1891.

55 D. Chen, A. Sahasrabudhe, P. Wang, A. Dasgupta, R. Yuan and S. Roy, Dalton Trans., 2013, 42, 10587-10596.

56 A. Sahasrabudhe and S. Roy, J. Mol. Eng. Mater., 2014, 2, 1440002.

57 S. Das, A. Misra and S. Roy, New J. Chem., 2016, 40, 994-1003. 58 A. Müller, E. Krickemeyer, J. Meyer, H. Bögge, F. Peters, W. Plass, E. Diemann, S. Dillinger, F. Nonnenbruch and M. Randerath, Angew. Chem., Int. Ed., 1995, 34, 2122-2124.

59 A. Muller, K. Das, E. Krickemyer and C. Kuhlmann, Inorg. Synth., 2004, 34, 191-200.

60 A. Müller, S. K. Das, V. P. Fedin, E. Krickemeyer, C. Beugholt, H. Bögge, M. Schmidtmann and B. Hauptfleisch, Z. Anorg. Allg. Chem., 1999, 625, 1187-1192.

61 A. Müller and C. Serain, Acc. Chem. Res., 2000, 33, 2-10.

62 T. Liu, E. Diemann, H. Li, A. W. Dress and A. Müller, Nature, 2003, 426, 59-62.

63 I. Brown and D. Altermatt, Acta Crystallogr., Sect. B: Struct. Sci., 1985, 41, 244-247.

64 T. Liu, J. Am. Chem. Soc., 2002, 124, 10942-10943.

65 M. S. A. Sher Shah, A. R. Park, K. Zhang, J. H. Park and P. J. Yoo, ACS Appl. Mater. Interfaces, 2012, 4, 3893-3901.

66 M. Boudart and G. Djéga-Mariadassou, Kinetics of Heterogeneous Catalytic Reactions, Princeton University Press, 2014.

67 A. Orlov, A. Roy, M. Lehmann, M. Driess and S. Polarz, J. Am. Chem. Soc., 2007, 129, 371-375.

68 A. Dhakshinamoorthy, S. Navalon, A. Corma and H. Garcia, Energy Environ. Sci., 2012, 5, 9217-9233.

69 A. Müller, E. Krickemeyer, H. Bögge, M. Schmidtmann and F. Peters, Angew. Chem., Int. Ed., 1998, 37, 3359-3363.

70 H. Sun, S. Liu, G. Zhou, H. M. Ang, M. O. Tadé and S. Wang, ACS Appl. Mater. Interfaces, 2012, 4, 5466-5471. 